\title{
ANALISIS KINERJA SIMPANG BERSINYAL PASAR PON MENGGUNAKAN PROGRAM SIMULASI PTV VISSIM
}

\author{
Juan Nicholas Aldo'), Budi Yulianto ${ }^{2)}$, Setiono ${ }^{3)}$ \\ 1)Mahasiswa Fakultas Teknik, Prodi Teknik Sipil, Universitas Sebelas Maret \\ 2),3)Pengajar Fakultas Teknik, Prodi Teknik Sipil, Universitas Sebelas Maret \\ Jl. Ir. Sutami No. 36A, Kentingan, Surakarta 57126, Telp. (0271) 647069, Fax 634524 \\ Email: juanunderstood@student.uns.ac.id
}

\begin{abstract}
The obstacle in transportation has become the main public problem that spread across the nation. The increasing number of the private vehicle ownership often causes traffic jams on the numerous public roads, especially in the city of Surakarta. In order to anticipate this kind of obstacle, the city officials of Surakarta revitalized the regular city public transport into Rapid Transport Bus or BRT (Bus Rapid Transit), which is called BST (Batik Solo Trans). On September 1st, 2010, BST with corridor number 1 started operating from Adi Soemarmo Airport to Palur and vice versa, going through Brigjend Slamet Riyadi street. Besides, to gain an easy access for corridor 1, the Contra Flow Bus Lane is needed on Brigjend Slamet Riyadi street. Accordingly, the additional control on the five-lane on the main street of Brigjend Slamet Riyadi is also necessary, especially on the signalized intersection in Pasar Pon or Simpang Bersinyal Pasar Pon, which is the signaled cross road that uses Fixed Time Controller system in operating the traffic. This research aimed at modelling and analyzing the work of the signalized intersection in Pasar Pon or Simpang Bersinyal Pasar Pon that uses FTC, Signal Optimization scenario, and the increase of Pedestrian Phase, which uses PTV VISSIM simulation program. The calibration and validation process were done on the basic model only to obtain more accurate data. In the calibration process, the Geoffrey E. Havers (GEH) statistics test was conducted towards the traffic flow on each side of the cross roads to acknowledge whether its model had been calibrated or not. Meanwhile, on the validation process, the researcher used T test towards the maximum queue length on every 10 (ten) mintues and the difference test towards the LV travel time to understand whether the data had been calibrated. As the results, this research can be concluded that Signal Optimization system affected significantly for the increase of the function of signaled intersection of Pasar Pon especially that can be seen from the delay and the length of the traffic queue. On the other hand, the increase of pedestrian phase can give lower ability due to the fact that there is additional phase time, the queue length, travel time, and the delay drastically increased than the existing condition and the signal optimization scenario
\end{abstract}

Keywords: : GEH Statistical Test, Pasar Pon Signalized Intersection, Pedestrian Phase, PTV VISSIM, Signal Optimalization.

\begin{abstract}
Abstrak
Masalah transportasi merupakan masalah publik yang kini mulai menjangkiti kota - kota atau daerah di Indonesia. Meningkatnya jumlah kepemilikan kendaraan pribadi menyebabkan meningkatnya tingkat kemacetan pada sejumlah ruas jalan, khususnya di kota Surakarta. Untuk mengantisipasi hal tersebut, Pemerintah Kota (Pemkot) Surakarta merevitalisasi angkutan umum perkotaan regular menjadi angkutan umum yang berbasis Bus Rapid Transit (BRT) yaitu Batik Solo Trans (BST). Pada tanggal 1 September 2010 BST Koridor 1 mulai dioperasikan, dengan rute Bandara Adi Soemarmo - Palur (PP) - via Jalan Brigjend Slamet Riyadi. Untuk memudahkan akses BST Koridor 1, perlu adanya sistem Contra Flow Bus Lane pada ruas Jalan Brigjend Slamet Riyadi. Sehubungan dengan hal tersebut, perlu diadakan pengendalian pada kelima simpang utama jalan Brigjend Slamet Riyadi, salah satunya pada Simpang Bersinyal Pasar Pon, yang merupakan simpang empat bersinyal yang menggunakan sistem Fixed Time Controller dalam pengoperasian lalu lintasnya. Penelitian ini bertujuan untuk memodelkan dan menganalisis kinerja Simpang Bersinyal Pasar Pon menggunakan sistem Fixed Time Controller, skenario optimalisasi sinyal, dan penambahan fase pedestrian menggunakan program simulasi PTV VISSIM. Proses kalibrasi dan validasi dilakukan pada base model agar mendapatkan hasil yang akurat dan mendekati kenyataan. Pada proses kalibrasi dilakukan uji statistik Geoffrey E. Havers (GEH) terhadap arus lalu lintas di lengan-lengan simpang untuk mengetahui apakah model telah terkalibrasi. Sedangkan pada proses validasi dilakukan uji t terhadap panjang antrian maksimum tiap interval 10 menit dan uji perbedaan relatif terhadap waktu perjalanan LV untuk mengetahui apakah model telah tervalidasi. Dari pemodelan dan analisis yang dilakukan, dapat disimpulkan bahwa sistem Optimalisasi Sinyal memberikan pengaruh yang cukup signifikan terhadap peningkatan kinerja Simpang Bersinyal Pasar Pon, terutama apabila dilihat dari tundaan dan panjang antrian. Sedangkan sistem penambahan fase pedestrian memberikan penurunan kinerja yang signifikan karena adanya penambahan waktu fase, sehingga panjang antrian, travel time, dan tundaan meningkat drastis dibandingkan kondisi eksisting dan skenario optimalisasi simpang.
\end{abstract}

Kata Kunci : Fase Pedestrian, Optimalisasi Sinyal, PTV VISSIM, Simpang Bersinyal Pasar Pon, Uji Statistik GEH. 


\section{PENDAHULUAN}

Masalah transportasi merupakan masalah publik yang kini mulai menjangkiti kota - kota atau daerah di Indonesia. Meningkatnya jumlah kepemilikan kendaraan pribadi menyebabkan meningkatnya tingkat kemacetan pada sejumlah ruas jalan, khususnya di kota Surakarta. Berdasarkan kajian Masyarakat Transportasi Indonesia (2005), terdapat kecenderungan penurunan penggunaan angkutan umum sebesar 1\% per tahun di kota-kota besar di Indonesia karena peningkatan kemacetan. Untuk mengantisipasi hal tersebut, Pemerintah Kota (Pemkot) Surakarta mencanangkan visi dan misi Solo Menuju Kota dengan Transportasi yang Berkelanjutan (Dishubkominfo Kota Surakarta, 2012). Dari beberapa program kerjanya, salah satunya adalah merevitalisasi angkutan umum perkotaan regular menjadi angkutan umum yang berbasis Bus Rapid Transit (BRT) yaitu Batik Solo Trans (BST) serta merevitalisasi angkutan kota (angkot) menjadi moda feeder yang operasionalnya terintegrasi dengan BST. Kota Surakarta tercatat sebagai salah satu kota yang memelopori transformasi pelayanan bus kota menjadi sistem bus transit, bahkan lebih dahulu dibandingkan Surabaya.

Sehubungan dengan adanya penerapan sistem Contra Flow Bus Lane pada ruas Jalan Brigjend Slamet Riyadi, maka perlu adanya pengendalian simpang, karena ruas jalan ini terdiri dari 5 simpang, dimana simpang - simpang tersebut mengakomodasi pergerakan kendaraan dari 3 arah, supaya mampu bekerja dengan efektif dan mengurangi kemungkinan konflik yang terjadi. Selain pengendalian simpang terhadap kendaraan, demi mewujudkannya kota yang sustainable, perlu diadakannya juga pengendalian simpang terhadap pedestrian, karena mulai membaiknya fungsi jalur pedestrian dan city walk pada ruas jalan ini. Sejauh ini, sistem pengendalian simpang yang digunakan adalah sistem Fixed Time Control, dimana sistem ini adalah sistem lampu lalu lintas yang memiliki durasi cycle time yang tetap. Sistem ini bagus untuk diterapkan pada situasi lalu lintas yang terbilang memiliki fluktuasi normal, tetapi kurang cocok untuk kondisi dengan fluktuasi yang tinggi.

Ruas Jalan Brigjen Slamet Riyadi memiliki 5 simpang, salah satunya adalah Simpang Bersinyal Pasar Pon. Simpang ini terdiri dari ruas Jalan Brigjend Slamet Riyadi, Jalan Diponegoro, dan Jalan Gatot Subroto. Simpang ini cenderung memiliki arus yang lebih tidak padat dibandingkan dengan keempat simpang yang lain. Untuk menindaklanjuti penanganan simpang demi berjalannya metode Contra Flow Bus Lane tersebut, maka diadakan analisis kinerja simpang menggunakan program simulasi PTV VISSIM, dimana dalam proses pengerjaannya dilakukan proses kalibrasi dan validasi agar mendapatkan hasil yang sesuai dengan keadaan lapangan beserta perubahannya setelah dimodelkan dalam skenario yang berbeda - beda.

\section{DASAR TEORI}

\section{Simpang}

Menurut Direktorat Jenderal Perhubungan Darat (1996), persimpangan adalah titik pertemuan atau percabangan jalan, baik yang sebidang maupun yang tidak sebidang. Persimpangan sebidang adalah persimpangan dimana berbagai jalan atau ujung jalan yang masuk ke persimpangan, mengarahkan lalu-lintas masuk ke jalur yang berlawanan dengan lalu-lintas lainnya, seperti misalnya persimpangan pada jalan-jalan kota. Persimpangan ini memiliki ketinggian yang sama. Terdapat empat jenis pergerakan arus lalu lintas yang terjadi pada persimpangan, yaitu berpotongan (crossing), bergabung (merging), berpisah (diverging), dan berjalinan (weaving).

\section{Lampu Lalu Lintas}

Menurut UU nomor 22 tahun 2009 tentang LLAJ, lampu lalu lintas atau biasanya disebut dengan Alat Pemberi Isyarat Lalu Lintas (APILL) adalah lampu yang berada pada kanan kiri lengan suatu persimpangan jalan, berupa tiang dengan tiga buah lampu dengan warna merah, kuning, dan hijau yang berfungsi untuk mengatur dan mengendalikan arus lalu lintas.

\section{Contra Flow Bus Lane (CFBL)}

Contra flow adalah keadaan dimana kendaraan menggunakan tambahan lajur yang diambil dari lajur dengan arah yang berlawanan. Pada umumnya, keputusan contra flow pada jalan raya diikuti dengan arahan dari polisi sebagai pihak yang berwenang mengatur lalu lintas jalan raya, dan hal tersebut diupayakan untuk dapat mengurangi kemacetan. Namun tidak sedikit pula pengendara kendaraan bermotor yang mengambil inisiatif melakukan contra flow tanpa arahan polisi (PT. Jasa Marga, 2012). 


\section{PTV VISSIM}

Program Vissim merupakan program yang dikembangkan oleh PTV (Planung Transportasi Verkehr AG) di Karlsruhe, Jerman. Nama ini berasal dari "Verkehr Städten - SIMulationsmodell" (bahasa Jerman untuk "Lalu lintas di kota - model simulasi"). Vissim dimulai pada tahun 1992 dan saat ini pemimpin pasar global. Vissim model simulasi telah dipilih untuk mengkalibrasi kondisi lalu lintas.

\section{Kalibrasi dan Validasi PTV VISSIM}

VISSIM digunakan untuk menyimulasi lalu lintas yang heterogen, tidak teratur dan komposisi lalu lintasnya terdiri dari berbagai tipe kendaraan (disebut mixed traffic). Proses kalibrasi dan validasi model perlu dilakukan agar adanya keyakinan bahwa model yang dibuat itu valid, yaitu hasil keluaran model mendekati hasil observasi. Dari analisa statistik dapat disimpulkan bahwa model yang di buat adalah valid, dimana parameter kinerja keluaran VISSIM model (waktu tempuh dan panjang antrian kendaraan) mendekati hasil observasi. Kalibrasi adalah proses menyesuaikan parameter untuk mendapatkan kesesuaian antara nilai simulasi dan data yang diamati. Data lalu lintas yang digunakan sebagai perbandingan dalam proses kalibrasi adalah jumlah arus lalu lintas di kaki-kaki simpang baik yang masuk ke simpang maupun ke luar dari simpang. Sedangkan validasi adalah penentuan apakah secara konseptual model simulasi dapat merepresentasikan pemodelan secara akurat (Hellinga et al, 1996). Validasi dilakukan berdasarkan jumlah volume lalu lintas dan panjang antrian.

Untuk menentukan validasi suatu model, perlu diadakannya uji penyesuaian (goodness of fit) antara hasil simulasi dan hasil observasi dalam proses kalibrasi dan validasi menggunakan beberapa metode yang diantaranya adalah:

1. Perbedaan Relatif (Relative Difference)

Perbedaan relatif adalah besaran nilai dengan membandingkan nilai perbedaan mutlak dengan nilai observasi dilapangan, sehingga nilai ini tidak memiliki satuan. Nilai perbedaan relatif dapat dihitung dengan persamaan [1] berikut:

Perbedaan Re latif $=\frac{(\text { NilaiModel }- \text { NilaiObservasi })}{\text { NilaiObservasi }} \ldots . .[1]$

2. Statistik Geoffrey E. Havers (GEH)

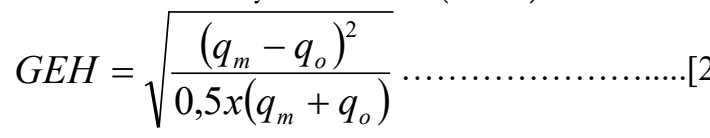

dengan:

$\mathrm{q}_{\mathrm{m}} \quad=\quad$ arus lalu lintas hasil Model

qo $\quad=\quad$ arus lalu lintas hasil Observasi

3. Independent Sample T-Test

Uji T-Test digunakan sebagai acuan yang menentukan apakah dua sample yang tidak sama memiliki rata rata yang berbeda. Uji T untuk varian yang sama (equal variance) menggunakan rumus Polled Varians :

$$
t=\frac{\bar{X}_{1}-\bar{X}_{2}}{\frac{\left(n_{1}-1\right) S_{1}^{2}+\left(n_{2}-1\right) S_{2}^{2}}{n_{1}+n_{2}+2}\left(\frac{1}{n_{1}}+\frac{1}{n_{2}}\right)} \ldots \ldots \ldots \ldots \ldots .[3]
$$

dengan:

$\mathrm{X}_{1}=$ Rerata sampel 1

$\mathrm{X}_{2}=$ Rerata sampel 2

$\mathrm{S}_{1} \quad=$ Deviasi Standar sampel 1

$\mathrm{S}_{2} \quad=$ Deviasi Standar sampel 2

$\mathrm{S}_{1}{ }^{2}=$ Variasi sampel 1

$\mathrm{S}_{2}{ }^{2}=$ Variasi sampel 2

$\mathrm{n}_{1} \quad=$ Jumlah data sampel 1

$\mathrm{n}_{2} \quad=$ Jumlah data sampel 2 
Cara mengetahui signifikansi hasil uji t bisa dilihat dari perbandingan danri $\mathrm{T}_{\text {hitung }}$ dan $\mathrm{T}_{\text {tabel }}$ (two tailed) dan hasil nilai $\mathrm{P}$ (two tailed). Apabila nilai $\mathrm{T}_{\text {hitung }}<$ dari $\mathrm{T}_{\text {tabel }}$ (two tailed) dan hasil $\mathrm{P}$ (two tailed) $>0,05$, maka perbedaan yang dihasilkan diterima.

\section{METODE}

\section{Pengumpulan Data}

Kebutuhan data dalam penelitian ini dibedakan menjadi dua, yaitu:

1. Data Primer

Data primer adalah data yang diambil langsung oleh peneliti dari survei (pengamatan) yang dilakukan di lapangan. Data primer yang dibutuhkan meliputi:
a. Geometri ruas jalan dan simpang
b. Volume lalu lintas (Pencacahan)
c. Komposisi lalu lintas
d. Panjang antrian kendaraan pada setiap lengan simpang
e. Kecepatan setempat untuk kendaraan
f. Waktu perjalanan

2. Data Sekunder

Data sekunder adalah data yang diperoleh oleh peneliti secara tidak langsung, bisa melalui perantara, seperti instansi terkait, sosial media, dan melalui narasumber seperti dosen, ataupun melalui studi literatur dan website ilmiah, ataupun melalui media lainnya yang terkait. Data sekunder yang biasanya diperlukan dalam penelitian ini diantaranya seperti data prasarana, tata guna lahan, fasilitas angkutan umum, pejalan kaki, pesepeda, parkir, karakteristik sistem jalan, dan foto udara melalui Google Maps yang digunakan sebagai background untuk membuat network simpang dalam program simulasi PTV VISSIM.

\section{Analisis Data}

Permodelan dari Simpang Bersinyal Pasar Pon dibuat atas dasar dari data - data yang didapatkan menggunakan program simulasi PTV VISSIM. Analisis dari model tersebut akan menghasilkan parameter kinerja simpang berupa panjang antrian, waktu perjalanan, dan tundaan.

\section{Kalibrasi dan Validasi Base Model}

Setelah melakukan tahapan modelling menggunakan VISSIM, tahap selanjutnya adalah proses kalibrasi dan validasi dengan kondisi eksisting. Di dalam penelitian ini, VISSIM digunakan untuk menyimulasi lalu lintas yang heterogen, tidak teratur dan komposisi lalu lintasnya terdiri dari berbagai tipe kendaraan (disebut mixed traffic). Proses kalibrasi dan validasi model perlu dilakukan agar adanya keyakinan bahwa model yang dibuat itu valid, yaitu hasil keluaran model mendekati hasil observasi. Dari analisa statistik dapat disimpulkan bahwa model yang di buat adalah valid, dimana parameter kinerja keluaran VISSIM model (waktu tempuh dan panjang antrian kendaraan) mendekati hasil observasi. 


\section{HASIL DAN PEMBAHASAN}

Sehubungan dengan keperluan data dalam penelitian ini, maka dilakukan survei kondisi lalu lintas, inventarisasi simpang dan waktu siklus lampu lalu lintas untuk membuat model dan menentukan kinerja Simpang Bersinyal Pasar Pon. Data yang didapatkan dari hasil survei yaitu data geometri simpang dan ruas jalan, waktu siklus lampu lalu lintas, volume lalu lintas, komposisi kendaraan, proporsi pergerakan, kecepatan kendaraan, panjang antrian , dan waktu tempuh. Data-data tersebut kemudian dianalisis dan dijelaskan lebih sebagai berikut.

\section{Hasil Kalibrasi dan Validasi}

Kalibrasi model dasar dilakukan dengan mengubah parameter-parameter secara berulang agar model mendekati kondisi lapangan. Dilakukan uji statistik GEH terhadap arus lalu lintas di lengan-lengan simpang untuk mengetahui signifikansi perbedaan antara jumlah arus lalu lintas hasil model dan hasil observasi. Uji statistik GEH dapat dinyatakan diterima apabila nilai GEH kurang dari 5 (GEH > 5). Pada Tabel 1 telah disajikan hasil uji statistic GEH pada jam puncak sore.

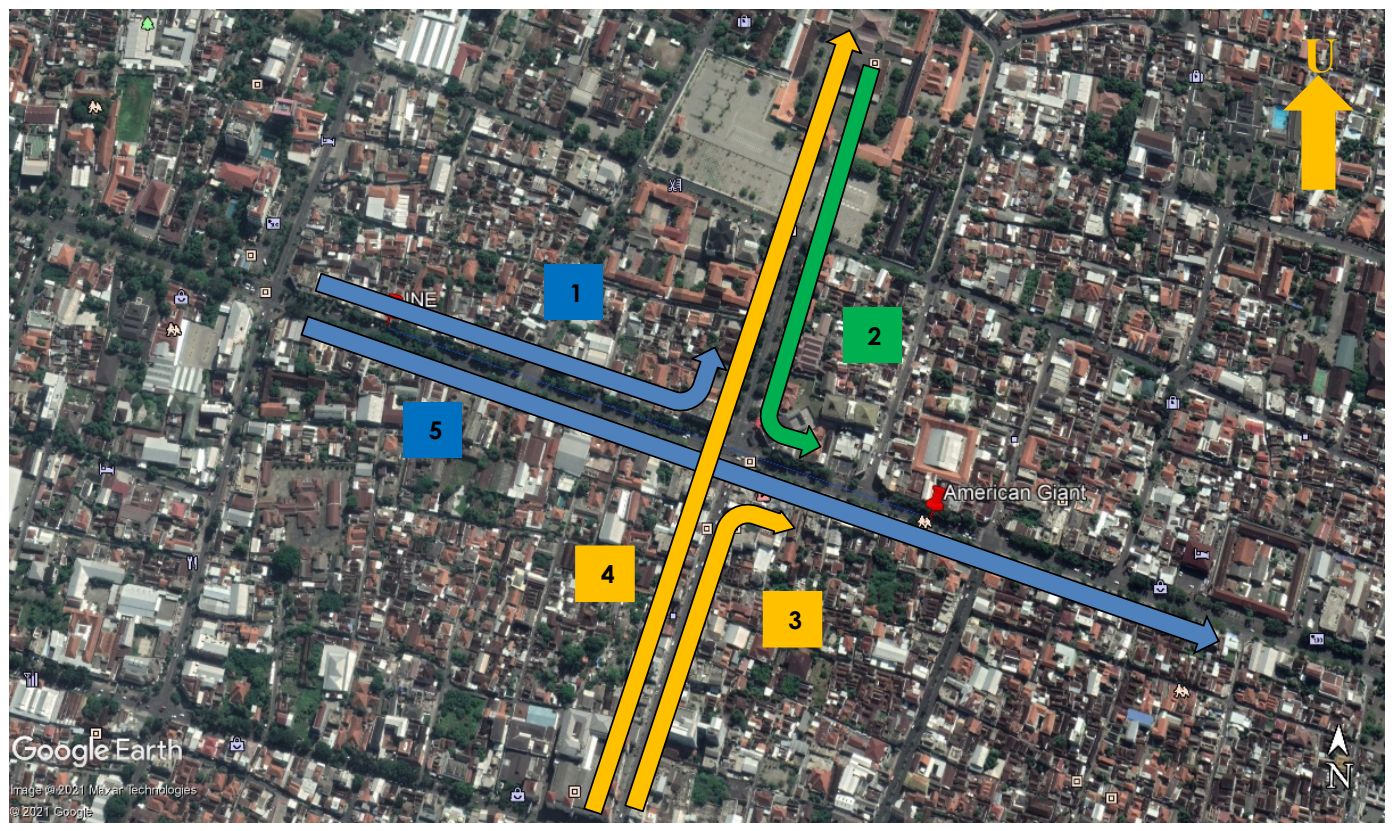

Gambar 1. Rute perjalanan yang diukur dalam analisis kinerja Simpang Pasar Pon kondisi eksisting

Pada Gambar 1, terdapat 5 titik pendekat yang digambarkan berdasarkan arah bergeraknya arus lalu lintas yang dimodelkan. Seperti nomor 1 menggambarkan arah barat ke utara, lalu nomor 2 dari arah utara ke timur, setelah itu nomor 3 menggambarkan arah selatan ke timur, dilanjutkan nomor 4 dari arah selatan ke utara, dan diakhiri dengan nomor 5 dari arah barat ke timur.

Tabel 1. Hasil uji statistik GEH arus lalu lintas pada jam puncak sore

\begin{tabular}{|c|c|c|c|c|c|c|c|c|c|}
\hline \multirow{3}{*}{ Lokasi } & \multicolumn{6}{|c|}{ q Model } & \multirow{3}{*}{$\begin{array}{c}\mathrm{q} \\
\text { Observasi }\end{array}$} & \multirow{3}{*}{$\begin{array}{l}\text { Nilai } \\
\text { GEH }\end{array}$} & \multirow{3}{*}{ Keterangan } \\
\hline & \multicolumn{5}{|c|}{ Run ke } & \multirow{2}{*}{$\begin{array}{l}\text { Rata- } \\
\text { rata }\end{array}$} & & & \\
\hline & 1 & 2 & 3 & 4 & 5 & & & & \\
\hline 1 & 2934 & 3013 & 2923 & 2881 & 272 & 2938 & 2931 & 0,1 & Diterima \\
\hline 2 & 398 & 430 & 395 & 393 & 35 & 404 & 394 & 0,5 & Diterima \\
\hline 3 & 2260 & 2210 & 2248 & 2201 & 216 & 2230 & 2206 & 0,5 & Diterima \\
\hline 4 & 1531 & 1547 & 1564 & 1499 & 119 & 1535 & 1546 & 0,3 & Diterima \\
\hline 5 & 3949 & 4000 & 3883 & 3848 & 274 & 3920 & 3993 & 1,2 & Diterima \\
\hline
\end{tabular}


Pada Tabel 1, bisa dilihat bahwa nilai GEH yang didapatkan pada kelima pendekat yang dimodelkan bernilai kurang dari 5, rata - rata dibawah 1 pada pendekat 1 sampai dengan 4, lalu 1,2 pada pendekat 5 yaitu bermula dari arah barat ke timur.

Validasi dilakukan untuk mengetahui apakah model yang dibuat sesuai dengan kondisi lapangan. Dilakukan uji kesesuaian pada setiap variabel pembanding untuk mengetahui signifikansi perbedaan antara output model dan data observasi lapangan. Uji kesesuaian yang dilakukan terhadap panjang antrian maksimum adalah uji t dengan hipotesis nol $\left(\mathrm{H}_{0}\right)$ yang menyatakan bahwa tidak ada perbedaan signifikan antara panjang antrian maksimum output model dan hasil observasi. Hasil analisis dinyatakan diterima apabila nilai $\mathrm{t}$ hitung lebih kecil daripada nilai $\mathrm{t}$ tabel $\left(\mathrm{t}_{\text {hitung }}<\mathrm{t}_{\text {tabel }}\right)$ dan $\mathrm{P}($ two-tailed $)>0,05$.

Tabel 2. Hasil uji t panjang antrian maksimum pada jam puncak sore

\begin{tabular}{|c|c|c|c|c|c|c|c|c|}
\hline \multirow[t]{2}{*}{ No. } & \multirow{2}{*}{$\begin{array}{l}\text { Lengan } \\
\text { Simpang }\end{array}$} & \multirow{2}{*}{$\begin{array}{l}\text { Interval } \\
\text { menit ke }\end{array}$} & \multicolumn{2}{|c|}{$\begin{array}{l}\text { Panjang Antrian } \\
\text { Maksimum (m) }\end{array}$} & \multirow[t]{2}{*}{ t hitung } & \multirow[t]{2}{*}{ t tabel } & \multirow[t]{2}{*}{$\mathbf{P}$} & \multirow[t]{2}{*}{ Keterangan } \\
\hline & & & Model & Observasi & & & & \\
\hline \multirow{6}{*}{1} & \multirow{6}{*}{ Barat } & $16: 41: 20$ & 66 & 85 & \multirow{6}{*}{1,375} & \multirow{6}{*}{2,228} & \multirow{6}{*}{0,199} & \multirow{6}{*}{ Diterima } \\
\hline & & $16: 51: 20$ & 75 & 81 & & & & \\
\hline & & $17: 01: 20$ & 84 & 76 & & & & \\
\hline & & $17: 11: 20$ & 93 & 78 & & & & \\
\hline & & $17: 21: 20$ & 86 & 81 & & & & \\
\hline & & $17: 31: 20$ & 90 & 72 & & & & \\
\hline \multirow{6}{*}{2} & \multirow{6}{*}{ Selatan } & $16: 40: 28$ & 40 & 40 & \multirow{6}{*}{0,557} & \multirow{6}{*}{2,228} & \multirow{6}{*}{0,590} & \multirow{6}{*}{ Diterima } \\
\hline & & $16: 50: 28$ & 43 & 38 & & & & \\
\hline & & $17: 00: 28$ & 52 & 45 & & & & \\
\hline & & $17: 10: 28$ & 49 & 40 & & & & \\
\hline & & $17: 20: 28$ & 47 & 45 & & & & \\
\hline & & $17: 30: 28$ & 44 & 55 & & & & \\
\hline
\end{tabular}

Pada Tabel 2, diperlihatkan bahwa nilai thitung yang dihasilkan kurang dari ttabel, lalu nilai P yang lebih dari 0,05 dimana pada pendekat barat adalah sebesar 0,199, dan pada pendekat selatan sebesar 0,590, sehingga hasil analisis yang dihasilkan bisa diterima.

Hasil uji kesesuaian pada tiap variabel pembanding dalam proses validasi pada jam puncak sore akan diterima apabila nilai perbedaan relatif dari hasil pengolahan data kurang dari $15 \%$.

Tabel 3. Hasil validasi waktu perjalanan sore

\begin{tabular}{|c|c|c|c|c|c|}
\hline \multirow{2}{*}{ No. } & \multirow{2}{*}{$\begin{array}{l}\text { Asal-Tujuan Perjal- } \\
\text { anan }\end{array}$} & \multicolumn{2}{|c|}{$\begin{array}{l}\text { Waktu Perjalanan Rata-rata } \\
\text { (detik) }\end{array}$} & \multirow{2}{*}{$\begin{array}{l}\text { Persentase Perbe- } \\
\text { daan Relatif }\end{array}$} & \multirow{2}{*}{ Keterangan } \\
\hline & & Model & Observasi & & \\
\hline 1 & Barat-Timur & 107,29 & 97 & $11 \%$ & Diterima \\
\hline
\end{tabular}

Pada Tabel 3 diperlihatkan bahwa nilai perbedaan relatif segmen barat - timur bernilai 11\%, dimana nilai tersebut dibawah 15\%. Hal ini menunjukkan bahwa base model dinyatakan valid dan sudah terkalibrasi untuk analisis selanjutnya. 


\section{SIMPULAN}

Program simulasi PTV VISSIM terbukti mampu digunakan untuk memodelkan lalu lintas dengan kondisi mix traffic seperti yang ada pada Simpang Pasar Pon. Dari hasil analisis berupa proses kalibrasi dan validasi, dapat disimpulkan bahwa model dari Simpang Bersinyal Pasar Pon yang telah dibuat dinyatakan valid, dengan hasil output model mendekati hasil observasi sesuai dengan syarat - syarat dari tiap pengujian yang dilaksanakan.

\section{UCAPAN TERIMAKASIH}

Ucapan terimakasih penulis haturkan kepada Bapak Budi Yulianto, S.T., M.Sc., Ph.D. dan Bapak Setiono, S.T., M.Sc. sebagai Dosen Pembimbing yang telah bersedia untuk membimbing penulis dalam penelitian ini. Ucapan terimakasih juga penulis haturkan kepada keluarga dan rekan penulis sekalian yang telah memberi support sehingga skripsi ini usai.

\section{REFERENSI}

Aryandi, Rama Dwi, dan Munawar, Ahmad., 2014, "Penggunaan Software VISSIM Untuk Analisis Simpang Bersinyal (Studi Kasus Simpang Mirota Kampus Terban Yogyakarta)".

Andreas, G.F., 2015, "Evaluasi Penerapan Sistem Contra Flow Bus Lane dengan Menggunakan Software VISSIM".

Fitrada, AG, dan Munawar, Ahmad, 2015, "Evaluasi Penerapan Sistem Contra Flow Bus Lane dengan Menggunakan Software VISSIM (Studi Kasus Jalan Prof. Yohanes dan Jalan C. Simanjuntak)”.

Google Maps, 2021, "Peta Lokasi Simpang Empat Pasar Pon Slamet Riyadi 7.570133,110.821924",https://www.google.com/maps/place/7\%C2\%B034'12.5\%22S+110\%C2\%B049'1 8.9\%22E, accesed: 3 Maret 2020.

Man, Loh, Yulianto, Budi., \& Setiono., 2017, "Analisis Kinerja Simpang Tiga Sriwedari dengan Fixed Time Control dan Demand Responsive Control pada Sistem Contra Flow Bus Lane", Matriks Teknik. Sipil, Vol 5 No 3, pp. $798-808$

Putri, Nurjannah Haryanti, dan Irawan, Muhammad Zudhy, 2015, "Mikrosimulasi Mixed Traffic pada Simpang Bersinyal dengan Perangkat Lunak VISSIM (Studi Kasus Simpang Tugu, Yogyakarta)", The 18th FSTPT International Symposium, Unila, Bandar Lampung, 28 August 2015.

Tamin, O. Z., 2000, "Perencanaan dan Pemodelan Transportasi 2nd ed”, Penerit ITB, Bandung.

Yulianto, Budi dan Setiono, 2019, "Analysis of One-Way System Implementation with Contra Flow Bus Lane in Supporting Sustainable Transportation Program”, ICETs AS 2018, Journal of Physic: Confrences series

Yulianto, Budi., 2013, "Kalibrasi dan Validasi Mixed Traffic Vissim Model". Media Teknik Sipil.

Yulianto, B., 2003, “Application of fuzzy logic to traffic signal control under mixed traffic conditions”. Traffic Engineering and Control. Vol 44 No 9, pp. 332-335. 